\title{
INFLUENCE OF A LASHING STRAP WINDING IN TENSIONING RATCHET ON THE RESULTS OF THE STRENGTH TESTS AND CYCLIC LOADING TESTS ACCORDING TO THE STANDARD EN 12 195-2
}

This article is focused on the results of the testing of the complete web lashing and the cyclic loading tests of selected lashing straps of three various producers according to the standard EN 12 195-2. It analyses how the quantity of winding in tensioning ratchet affects the results of these tests, whereas it compares the results of the straps wound 21/4 times around the rotating axis (as is correct according to the standard) and those wound 11/4 times around the rotating axis (as is not enough quantity of a winding). The article concludes that the influence of the winding on elongation of straps as well as on operating life of the straps is strong. Damages on particular parts of complete lashing straps, which were found out within these tests, are also presented in the article.

Keywords: Lashing straps, cyclic loading tests, tests of the complete web lashing, elongation, force at break.

\section{Introduction}

Lashing straps made of synthetic fibres are very often used for cargo securing in road transport because of their advantages, such as low weight, sufficient length, simple and fast handling and relatively low price of standard types. Among them, the $50 \mathrm{~mm}$ wide polyester lashing straps with 2500 daN lashing capacity are the most often used to secure heavier cargo, e. g. palletized cargo [1]. Requirements for performance and testing of textile lashing straps and tensioning devices are defined in the standard EN 12 195-2. It prescribes type tests for new types of straps as well as production tests which have to be carried out continuously during the production. It prescribes the following type tests to be performed on standard combination of lashing straps with the ratchet:

- tensile test of textile webbings (without tensioning device and end fittings),

- testing of the complete web lashing,

- test of pre-tension ability of tensioning device (ratchet),

- test of the ability to release under tension,

- cyclic loading test of tensioning device,
- strength test of the ratchet handle,

- test of recoil.

The first two tests listed above have to be performed also continuously during production of lashing straps as so called production tests. The standard EN 12 195-2 prescribes a way of sampling and a sampling rate for the production tests.

In practice, inferior lashing straps and their tensioning devices (ratchets) are also sold on the market, whereas it is not possible to recognize their low quality visually without professional testing. But high forces can act on the straps in practice, mainly for short-term during emergency braking or evasive manouvering [2 and 3]. This may cause a break or loosening of such inferior (or damaged) lashing straps and inertial forces may cause a movement of loose cargo. As a consequence, it means not only material damages and losses, but also a threat for a driver, other road traffic users and nearby persons. The driver can not avoid emergency braking or manouvering in most cases, because this need is often caused by other road traffic users. Moreover, traffic accidents of heavy vehicles affect and endanger other road traffic users severely [4]. Results of the tests performed by the University of Zilina point at the fact that not all lashing straps available

\footnotetext{
* ${ }^{1}$ Jan Zamecnik, ${ }^{1}$ Juraj Jagelcak, ${ }^{2}$ Sven Sokjer-Peterssen, ${ }^{3}$ Tomas Hvojnik, ${ }^{3}$ Michal Lipka

${ }^{1}$ Department of Road and Urban Transport, Faculty of Operation and Economics of Transport and Communications, University of Zilina, Slovakia, ${ }^{2}$ MariTerm AB, CEO, Hoganas, Sweden

${ }^{3}$ Forwarding and Logistics at the Department of Road and Urban Transport, Faculty of Operation and Economics of Transport and Communications, University of Zilina, Slovakia

E-mail: jan.zamecnik@fpedas.uniza.sk
} 
on market comply with the quality and safety requirements [5]. Tests described in this article consist of the tests of the complete web lashing according to 6.4. of the standard EN 12 195-2 and the cyclic loading tests according to 6.5.3. of the standard. These tests were performed on samples of straps made by three various producers. The influence of the quantity of winding in tensioning ratchets on test results was studied. The tests confirmed strong influence of the quantity of winding of webbing in ratchets on the tests results.

\section{Test of the complete web lashing}

The lashing capacity (LC) stated on lashing strap labels means the maximum force for use in straight pull that a web lashing is designed to sustain in use [6]. The standard EN 12 195-2 prescribes that a new complete lashing strap consisting of a textile webbing, tensioning ratchet and end fittings has to withstand a load equivalent to $1.25 \mathrm{LC}$ acting during one minute without any permanent deformation or any other defect which affects its function. Subsequently, the strap should be inspected. No deformations on any of its parts, seam failure or slippage of the textile webbing through the tensioning device should occur. Tensioning devices or components with moving parts should fully retain their function and a space between a strap and a webbing slot of tensioning device should not be less than 2 percent of width of the strap. When the complete web lashing complied with this part of the test, it has subsequently to withstand a load equivalent to at least 2 LC without failure (safety factor 2). Testing of the complete web lashing should be performed with $2 \frac{1}{4}$ turns of web lashing around the rotating axis of the ratchet. As a part of this test it has to be checked, whether no sharp edges are in contact with the webbings or with the operator's hands, because it would reduce the lashing capacity of the strap or injure the operator respectively [6].

\section{Cyclic loading test of tensioning device}

Cyclic loading test of tensioning device is an important test, because it shows whether the strap exposed to cyclic, alternating load does not elongate excessively or release in a winding around the rotating axis. A complete lashing strap is exposed to 100 cycles between $0.2 \mathrm{LC}$ and $1 \mathrm{LC}$ where each cycle should last at least 2.5 seconds $^{1}$. The standard EN 12 195-2 prescribes maximum allowed elongation within 100 cycles for lashing straps with particular lashing capacities. The straps with LC $=2500$ daN must not elongate more than $20 \mathrm{~mm}$. The test has to be carried out with $2 \frac{1 / 4}{4}$ turns of web

${ }^{1}$ Before that, it is loaded in straight pull by a force equivalent to $\mathrm{LC}$ and then the load is reduced to $0.2 \mathrm{LC}$ lashing around the rotating axis of a ratchet. The sample used for the cyclic loading test may be used for the determination of the breaking force [6].

Repetitive cyclic load of the straps used for cargo securing in containers on vessels or in semi-trailers transported on ferries may occur e.g. in sea transport due to waves. The most critical is the sea area $\mathrm{C}$ and transverse direction where we have to consider inertial forces up to $0.8 \mathrm{G}$. In longitudinal direction (forwards and backwards) the securing effect of friction is significantly lowered. Bigger waves cause bigger inclinations of vessels and higher forces in lashing straps, and this effect repeats again and again [7 and 8].

\section{Straps used for the tests}

We used tensioning devices made by two different producers and loose ends by three producers of webbing loose ends to carry out the tests. Although the standard EN 12 195-2 requires these tests to be performed with $2 \frac{1}{1} 4$ turns of web lashing around the rotating axis of ratchet, we also compared results of the tests performed correctly according to the standard with $2 \frac{1 / 4}{4}$ turns of winding in a ratchet with those performed with similar straps with insufficient $1 \frac{1 / 4}{4}$ turns of winding in a ratchet. ${ }^{2}$ Our tests were performed on testing machine Testometric M500-100CT in the laboratory of the Department of road and urban transport of the University of Zilina. The tests were carried out with $1 \mathrm{~m}$ long samples (only the sample of old, worn strap OFS1/OL1 was lengthened to $2 \mathrm{~m}$ to examine, on which of the worn and damaged places the strap breaks).

We marked the tensioning devices used for the tests with a marking consisting of three letters and one digit. The first letter means a marking of producer (letters "A" or "B"), the second one is the letter " $F$ " meaning that the sample is a fixed end containing tensioning device, the third letter distinguished the tensioning devices with short ratchets (letter "S") and those with long ratchets (letter "L"). A digit at the end was a serial number of the same sample type. Loose ends without tensioning devices were marked similarly with a difference that the marking consisted only of two letters (the first letter "A", "B" or "C" meaning different producers and the second letter " $\mathrm{L}$ " meaning that the sample is a loose end) and a serial number. For example, marking AFS1 means the first sample of a fixed end with short ratchet made by producer A. For comparison, a strength test of an old and worn strap was also carried out. All the straps used for the testing had a lashing capacity of 2500 daN and producer's declared elongation up to $7 \%$ in a force equivalent to $\mathrm{LC}$.

${ }^{2}$ Hovewer, $1 \frac{1 / 4}{4}$ turn is required for the measurement of Standard tension force according to 6.5 .1 of EN 12195-2. 
5. Comparison of the results of the testing of the complete web lashing and cyclic loading tests of lashing straps carried out with $1 \quad 1 / 4$ and 2 1/4 turns of winding in a ratchet

Results of the tests of lashing straps confirmed that a quantity of winding in ratchet strongly affects strength, elongation and damages of the straps during such tests. Our tests were carried out with the same samples firstly tested by the cyclic loading tests and subsequently by the tests of the complete web lashing. Results of these tests are given in Table 1 in absolute values (values in milimeters rounded off to one decimal) and in Table 2 in percents of required values. Particular colours used in the tables mark comparable samples.

The results given above in Tables 1 and 2 clearly show that the quantity of a winding in a ratchet affects strongly an elongation of the straps after cyclic loading tests. All samples tested with $1 \frac{1 / 4}{4}$ turns of winding reached significantly higher elongation after 100 cycles than that is a maximum allowed value. In some cases, this elongation exceeded the allowed value several times. The worst result was measured on the sample AFS2/AL2, which exceeded it 7.6 times. On the other hand, both samples of the same type tested with $21 / 4$ turns of winding in a ratchet met the prescribed requirements, because their elongation reached 63.44 and $68.29 \%$ of maximum allowed elongation of $20 \mathrm{~mm}$. All the samples (same or comparable to those tested with $1 \frac{1 / 4}{4}$ turns of winding) tested with $21 / 4$ turns of winding met the requirements of the standard for cyclic loading tests except of the sample AFL3/ AL6, where a severe qualitative fault occured, because a break of the ratchet split pin occured just in the first cycle of cyclic loading tests at force $1473 \mathrm{daN}$. It affected the final result of the cyclic loading test, because this damage caused a decrease of force and the strap was released by $10 \mathrm{~mm}$ immediately (Fig. 1).

If good-quality ratchets with correct quantity of winding are used, run of elongation within particular cycles of the cyclic loading tests has a logarithmic character where after higher elongation between several first cycles, further elongation in next cycles is relatively stable and low. But if insufficient, poor-quality ratchets or ratchets with a low quantity of winding (as in our tests with $1 \frac{1 / 4}{4}$ turns of winding in ratchets) are used, the elongation between each cycle is

Results of the cyclic loading tests (elongation) and the tests of complete web lashing (elongation at force equivalent to LC and force at break)

Table 1

\begin{tabular}{|c|c|c|c|c|c|c|}
\hline \multirow[t]{2}{*}{$\begin{array}{l}\text { Combination of } \\
\text { samples }\end{array}$} & \multicolumn{2}{|c|}{$\begin{array}{l}\text { Elongation after cyclic loading tests } \\
{[\mathrm{mm}]}\end{array}$} & \multicolumn{2}{|c|}{$\begin{array}{l}\text { Elongation at force equivalent to LC } \\
{[\mathrm{mm}]}\end{array}$} & \multicolumn{2}{|c|}{ Force at break [daN] } \\
\hline & $\begin{array}{l}1 \frac{1}{1 / 4} \text { turns of } \\
\text { winding }\end{array}$ & $\begin{array}{l}21 / 4 \text { turns of } \\
\text { winding }\end{array}$ & $\begin{array}{l}1 \frac{1 / 4}{4} \text { turns of } \\
\text { winding }\end{array}$ & $\begin{array}{l}21 / 4 \text { turns of } \\
\text { winding }\end{array}$ & $\begin{array}{l}1 \frac{1}{1 / 4} \text { turns of } \\
\text { winding }\end{array}$ & $\begin{array}{l}21 / 4 \text { turns of } \\
\text { winding }\end{array}$ \\
\hline AFS1/AL1 & 94.1 & 12.7 & 5.5 & - & 3549 & - \\
\hline AFS2/AL2 & 152.5 & - & 4.8 & - & 5108 & - \\
\hline AFS3/AL5 & - & 13.7 & - & 6.1 & - & 5163 \\
\hline AFS1/CL1 & 66.7 & - & - & 4.9 & - & 5540 \\
\hline AFL1/AL3 & 70.7 & - & 3.9 & - & 3813 & - \\
\hline AFL1/AL6 & - & 7.9 & - & 6.4 & - & 5352 \\
\hline AFL2/AL4 & 57.1 & - & 3.6 & - & 4228 & - \\
\hline AFL3/AL6 & - & $21.6^{3}$ & - & - & - & - \\
\hline AFL1/CL2 & 33.6 & 11.0 & - & 5.1 & - & 5532 \\
\hline BFL2/AL3 & 103.1 & - & - & - & - & - \\
\hline BFL1/BL1 & 62.1 & 14.4 & - & 7.1 & - & 4793 \\
\hline BFL2/BL2 & 45.1 & 8.9 & - & - & - & - \\
\hline BFL1/CL3 & 31.7 & 10.9 & - & 4.6 & - & 4724 \\
\hline BFL2/CL4 & 34.6 & 10.6 & - & 4.7 & - & 5680 \\
\hline OFS1/OL1 & - & - & - & 5.7 & - & 3302 \\
\hline Mean value ${ }^{4}$ & 68.3 & 11.3 & 4.5 & 5.6 & 4175 & 5255 \\
\hline
\end{tabular}

Source: Authors

${ }^{3}$ In this case, a break of the ratchet split pin occured just in the first cycle of the cyclic loading tests. This caused that the sample was elongated by 10 $\mathrm{mm}$ immediately. If this damage did not occure, the requirement of $20 \mathrm{~mm}$ elongation as a maximum would be probably met, but occurence of such a damage is a severe qualitative fault of the ratchet.

${ }^{4}$ Except of the sample OFS1/OL1 
Results of the cyclic loading tests (elongation) and the tests of complete web lashing (elongation at force equivalent to LC and force at break) in relative expression (results which do not meet requirements of the standard EN 12 195-2 are red coloured)

Table 2

\begin{tabular}{|c|c|c|c|c|c|c|}
\hline \multirow[t]{2}{*}{$\begin{array}{l}\text { Combination of } \\
\text { samples }\end{array}$} & \multicolumn{2}{|c|}{$\begin{array}{l}\text { Elongation after cyclic loading tests } \\
\text { [\% of maximum allowed value] }\end{array}$} & \multicolumn{2}{|c|}{$\begin{array}{l}\text { Elongation at force equivalent to LC } \\
\text { [\% of maximum allowed value] }\end{array}$} & \multicolumn{2}{|c|}{$\begin{array}{l}\text { Safety coefficient - ratio of real force at } \\
\text { break and lashing capacity of a strap }\end{array}$} \\
\hline & $\begin{array}{l}1 \frac{1 / 4}{4} \text { turns of } \\
\text { winding }\end{array}$ & $\begin{array}{l}21 / 4 \text { turns of } \\
\text { winding }\end{array}$ & $\begin{array}{l}1 \frac{1}{4} \text { turns of } \\
\text { winding }\end{array}$ & $\begin{array}{l}2 \frac{1 / 4}{4} \text { turns of } \\
\text { winding }\end{array}$ & $\begin{array}{l}1 \frac{1 / 4}{4} \text { turns of } \\
\text { winding }\end{array}$ & $21 / 4$ turns of winding \\
\hline AFS1/AL1 & 470.4 & 63.4 & 78.7 & - & 1.42 & - \\
\hline AFS2/AL2 & 762.6 & - & 68.1 & - & 2.04 & - \\
\hline AFS3/AL5 & - & 68.3 & - & 87.8 & - & 2.07 \\
\hline AFS1/CL1 & 333.3 & - & - & 69.7 & - & 2.22 \\
\hline AFL1/AL3 & 353.6 & - & 56.2 & - & 1.52 & - \\
\hline AFL1/AL6 & - & 39.7 & - & 91.1 & - & 2.14 \\
\hline AFL2/AL4 & 285.7 & - & 52.0 & - & 1.69 & - \\
\hline AFL3/AL6 & - & $108.2^{3}$ & - & - & - & - \\
\hline AFL1/CL2 & 167.8 & 54.9 & - & 72.9 & - & 2.21 \\
\hline BFL2/AL3 & 515.7 & - & - & - & - & - \\
\hline BFL1/BL1 & 310.7 & 72.0 & - & 101.7 & - & 1.92 \\
\hline BFL2/BL2 & 225.3 & 44.5 & - & - & - & - \\
\hline BFL1/CL3 & 158.6 & 54.5 & - & 65.3 & - & 1.89 \\
\hline BFL2/CL4 & 173.0 & 52.8 & - & 67.2 & - & 2.27 \\
\hline OFS1/OL1 & - & - & - & 82.1 & - & 1.32 \\
\hline Mean value $^{4}$ & 341.5 & 62.0 & 63.8 & 79.4 & 1.67 & 2.10 \\
\hline
\end{tabular}
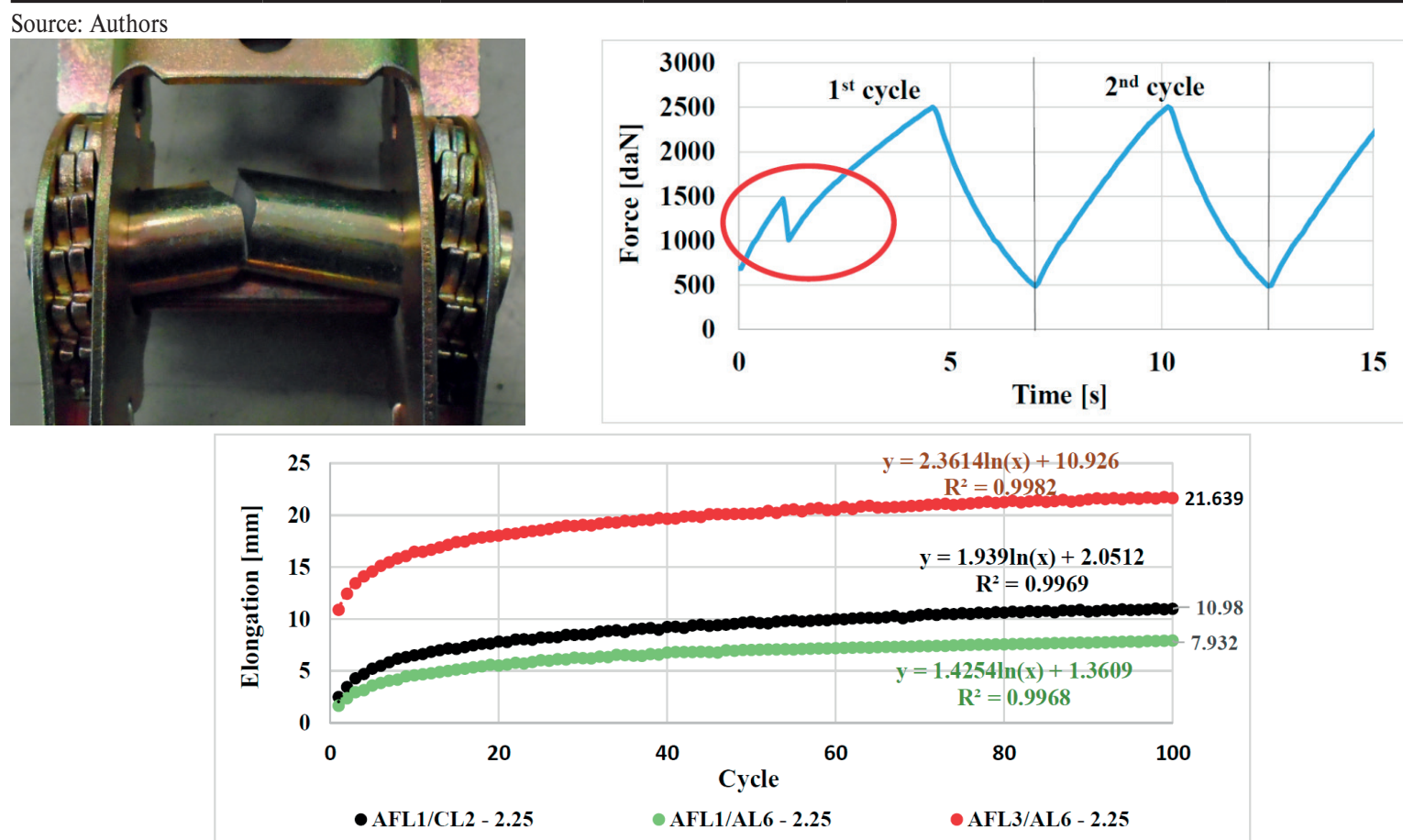

Source: Authors

Fig. 1 The split pin of the ratchet AFL3 which broke just after the first cycle of cyclic loading tests (up on the left), influence of this damage on the run of force during the cyclic test (up on the right) and run of elongation within particular cycles of the cyclic loading test in comparison with the second sample of the same type complete lashing strap without this damage AFL1/AL6 and with another sample with the same type ratchet and other type strap AFL1/CL2 (down)

${ }_{5}^{5}$ The standard prescribes a minimum safety coefficient 2 for new straps, because this coefficient is considered to cover worsening of their characteristics due to use and standard wear. 


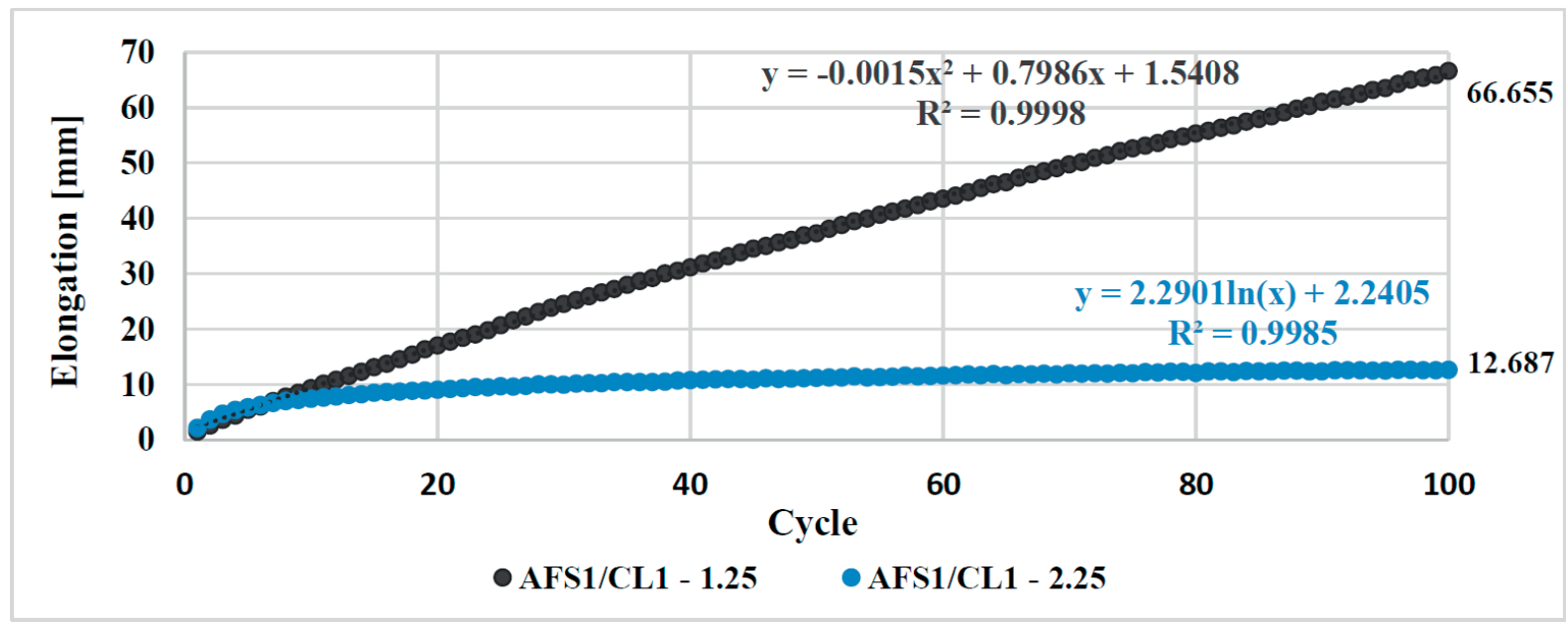

Source: Authors

Fig. 2 Run of elongation of the same type of lashing strap and ratchet sample AFS1/CL1 tested with 11/4 and with 21/4 turns of winding in the ratchet - logarithmic run for 21/4 turns of winding in the ratchet, linear run for 11/4 turns of winding in the ratchet

almost linear throughout the test and the strap loose evenly during whole test performance. Figure 2 compares elongation of two samples of the same type of lashing strap with $1 \frac{1 / 4}{4}$ and $2 \frac{1 / 4}{4}$ turns of winding in a ratchet. If $1 \frac{1 / 4}{4}$ turns of winding in a ratchet is used, a strap is sequencionally pulled out from the ratchet winch in each cycle, which causes high final elongation. It means that such straps are not capable to hold lashing forces and the webbing is subsequently released from the ratchet in the case of repeatedly occuring load caused by dynamical strain during transport. This may cause movement of cargo, danger and in the worst cases also a traffic accident due to loss of cargo securing (mainly in the case of transport of heavy pieces of cargo). In extreme cases, a lashing strap may be completely pulled out from a ratchet before the cyclic loading tests are finished. Other research showed that some types of poor-quality ratchets, which are frequently sold on the market and used in practice, reach with $2 \frac{1 / 4}{4}$ turns of winding in the ratchet the similar results of elongation and pulling out from the ratchets as our straps tested with $1 \frac{1}{1} 4$ turns of winding [9].

When the cyclic loading tests with $1 \frac{1 / 4}{4}$ turns of winding in a ratchet were performed and the lashing straps were pulled out from the ratchets, edges of the straps were damaged due to contact of textile web lashing with sharp edge of the tensioning ratchet (Fig. 3), which came to be placed slightly askew due to releasing of the web lashing strap. In some cases (with straps made by producer A) the edges of the straps were severely damaged and these damages affected results of the
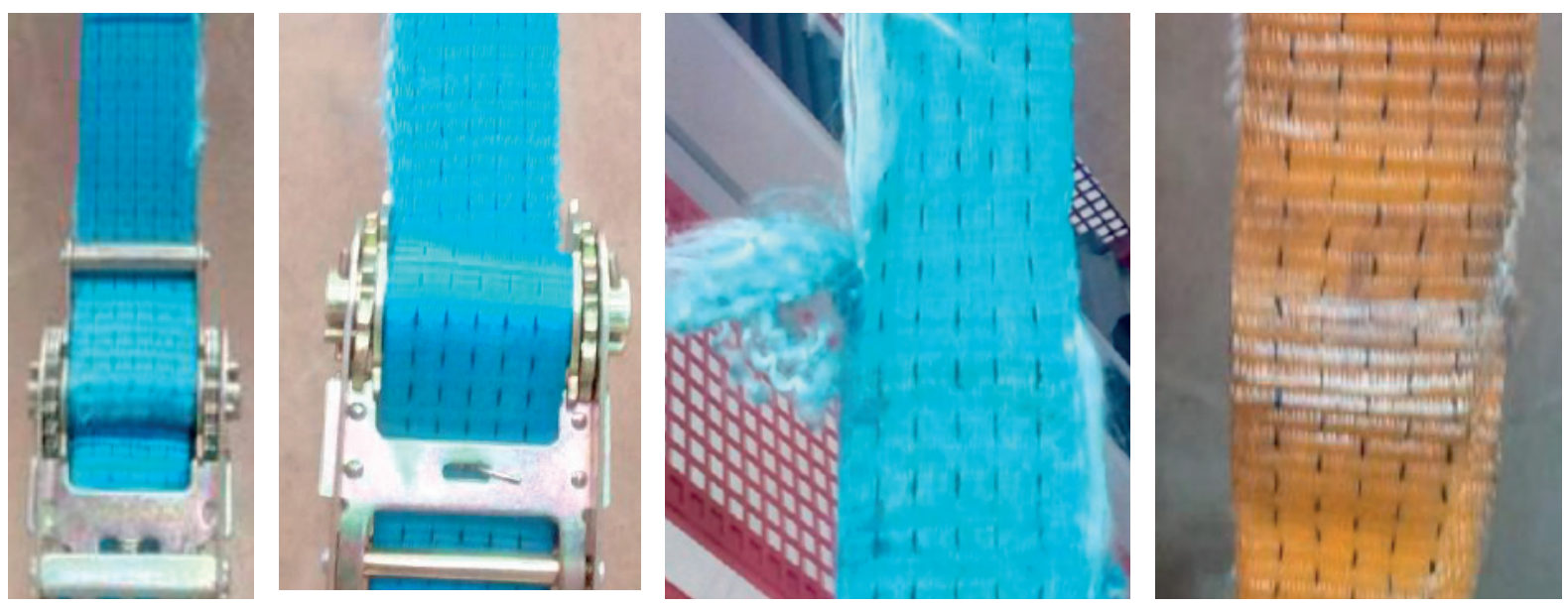

Source: [10]

Fig. 3 Tested lashing straps after cyclic loading tests performed with 1 1/4 turns of winding in a ratchet. From the left are samples: BFL2/ AL3, AFS2/AL2 (this sample met the requirements of strength test reaching force at break 5108 daN), AFS1/AL1 (this sample did not meet the requirements of strength test reaching force at break 3549 daN) and AFS1/CL1 
strength tests performed subsequently after the cyclic loading tests. Such damaged lashing straps did not withstand a force equivalent to double lashing capacity as is required by the standard EN 12195-2 (see results of the samples AFS1/AL1, AFL1/AL3 and AFL2/AL4, where the strength tests were carried out after cyclic loading tests). When the cyclic loading tests were carried out with $2 \frac{11}{4}$ turns of winding in ratchet, no such damages occured.

Also the straps made by producer B tested with $1 \quad 1 / 4$ turns of winding in ratchet reached excessive elongation, but damaging of their edges was smaller than on the straps of producer A. In the tests of the complete web lashing the following parameters were observed: elongation at force equivalent to $\mathrm{LC}$ and $1.25 \mathrm{LC}$, deformations and movement of the parts of the complete lashing strap after the load equivalent to $1.25 \mathrm{LC}$ acting during one minute as well as force at break, which should reach at least double LC. No movement of the textile webbing in ratchet or permanent deformations of any parts of the complete web lashing which may negatelively affect its function may occur after a load equivalent to $1.25 \mathrm{LC}$ acting during one minute. No deformations on any of tested long ratchets were observed, but some small deformations (dishing) of split pins on the short ratchets AFS1 - AFS3 were observed (Fig. 4). Damages on the edges of webbing, which had occured during cyclic loading tests on some samples, became yet worsened, but no sample broke during this part of the testing. Elongation during one minute of holding the force at $3125 \mathrm{daN}(1.25 \mathrm{LC})^{6}$ reached $0.2-0.4 \%$ in most of the cases (regardless of the quantity of winding) and $0.5-0.6 \%$ on the samples AFL1/AL6, AFS3/AL5 and on the sample of old and worn strap OFS1/OL1 (each of them with $2 \frac{1 / 4}{4}$ turns of winding in ratchet). These three samples also reached the worst results of elongation at the tests of the complete web lashing at all.

Tested short ratchets reached worse results of elongation at $1.25 \mathrm{LC}$ (elongation $6.204 \%-7.34 \%$ at the beginning of acting such force and $6.42 \%-7.91 \%$ at the end) than tested new long ratchets (elongation $4.07 \%-5.92 \%$ at the beginning of acting the force and $4.31-6.43 \%$ at the end). The highest elongation at this test was measured on the old and worn strap, where the results were $7.79 \%$ at the beginning and $8.30 \%$ at the end of holding the force equivalent to $1.25 \mathrm{LC}$.

Results of the tests in Tables 1 and 2 show that higher elongation (at the force equivalent to LC) was observed in the case when $2 \frac{1}{4}$ turns of winding in ratchet were used in comparison with tests when $1 \frac{1}{4}$ turns of winding were used. It was caused by compressing of bigger quantity of webbing wound around the rotating axis of a ratchet.

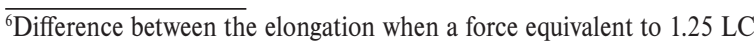
was reached and the elongation after a minute of holding this force.

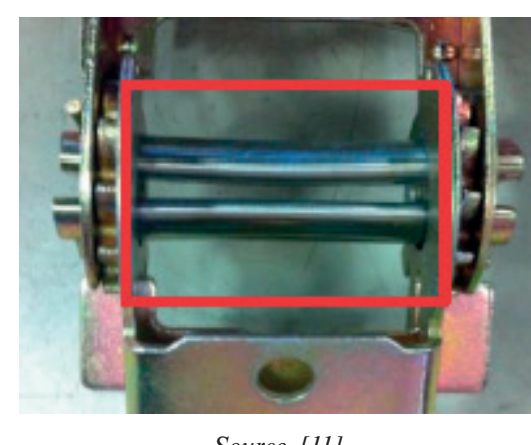

Source: [11]

Fig. 4 Slightly deformed (dished) split pin of short ratchet IFS1 after the test with force 1.25 LC held for 1 minute (first part of testing of the complete web lashing)

The last part of the testing of the complete web lashing, tests of strength, showed that a force at break was different for the samples tested with $1 \frac{1}{4}$ and $2 \frac{1}{4}$ turns of winding in ratchet. This difference was caused mainly due to damages on webbing of the samples tested with $1 \frac{1 / 4}{4}$ turns of winding, which had occured during previous cyclic loading tests (Fig. 3) while the samples tested with $2 \frac{1}{4}$ turns of winding were tested almost undamaged. But a quantity of winding in a ratchet also affects the strength of straps (force at break) because a place near a rotating axis of ratchet, where a winding ends, is a typical place of break of sufficient-quality and undamaged straps. When a low quantity of winding is wrapped around rotating axis, the split pin can act as a sharp edge when a high force acts on a strap. Also if an end fitting of a lashing strap has sharp edges like some of flat hooks, these edges may become the weakest part of the complete lashing strap, because the webbing may break just on these edges. Therefore, using of such end hooks is wrong in general [1].

In our case, all the straps and ratchets made by producer A complied with the requirements of the standard EN 12 195-2, if they were tested with $2 \frac{1 / 4}{4}$ turns of winding in ratchet and have not been damaged before the strength tests. But only one out of four samples of the same producer passed the test requirements with $1 \frac{1 / 4}{4}$ turns of winding. The other three samples had lowered strength to $1.42-1.69$ LC (71 $84.5 \%$ of the level prescribed by the standard) due to damaged edges of webbing. The straps and ratchets of other producers were tested only with $2 \frac{1}{4}$ turns of winding in ratchet.

An interesting situation occured with the straps made by producer B. These straps did not become damaged (neither on edges) during the cyclic loading tests performed with $1 \frac{114}{4}$ turns of winding despite of excessive elongation (pulling out from ratchet). But a dangerous problem occured on one of the fixed ends. The fixed end BFL1 was used for two tests, firstly with the loose end BL1 of the same producer (the webbing of this loose end broke at the force $4793 \mathrm{daN}$ ). Subsequently the fixed end was tested with the loose end CL3 by other producer 


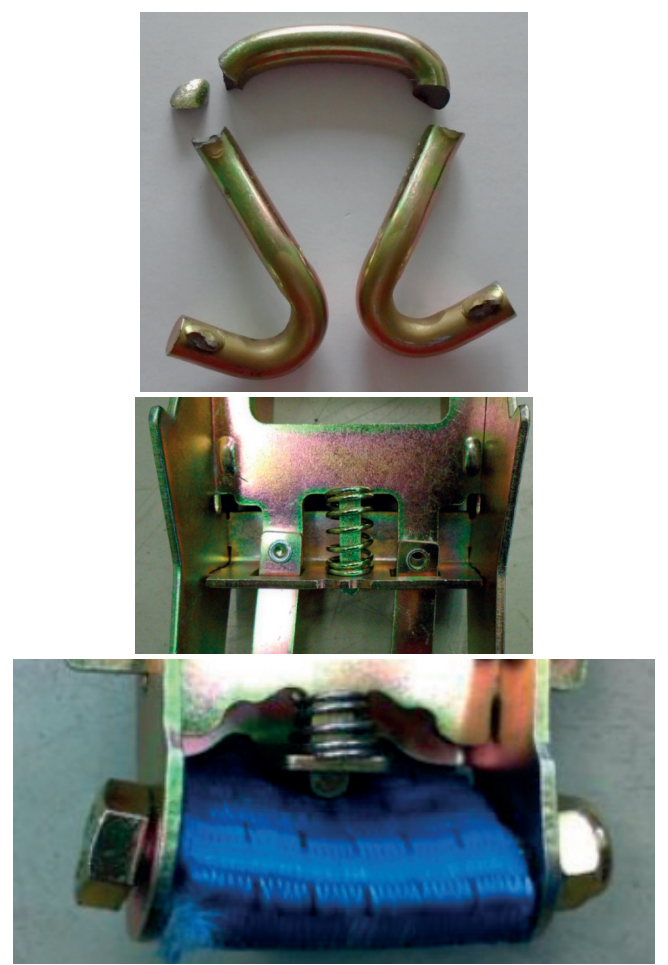

Source: Authors

Fig. 5 Broken end hook of the fixed end BFL1 before the force equivalent to double LC was reached (up on the left) and damages on the fixed end BFL2 - outage of rivet (up on the right) and bowed screw (down)

and the end hook of the fixed end BFL1 was completely broken into 4 parts at this test at the force $4724 \mathrm{daN}$, yet under required level of 2 LC. Another fixed end BFL2 met the test requirements, but it became also the weakest part of the tested combination with the strap of other producer CL4. The ratchet broke and one of the rivets fell away, and as a consequence of this, this tensioning ratchet was no longer usable due to dysfunctional releasing device. In addition to this, a screw holding the fixed end of the strap webbing was markedly bowed after the test. These damages are shown in Fig. 5.

The diagram in Fig. 6 shows a run of force and elongation of the selected samples of complete lashing straps during the strength tests (the final part of testing of the complete web lashing). The strap of the above stated sample BFL1/BL1 with the force at break 4793 daN have been gradually breaking yet by the force $3000 \mathrm{daN}$.

\section{Conclusion}

These tests comfirm the importance of quantity of winding in a ratchet when lashing straps are used. Results of the tests clearly prove that if the quantity of winding in ratchet is too low, the lashing straps fail in the cyclic loading tests, where they elongate abnormally (our samples exceeded the maximum allowed elongation according to the standard EN 12 195-2 by $53-663 \%$ ), derail from the tensioning ratchet and edges of their webbing are being damaged in contact with ratceht edges. Therefore, too low quantity of winding contributes not only to lowering durability of lashing straps, but also to safety risks resulting from the possibility of loss the securing capability of the straps in case such repetitive load occurs during transport. It may result in damages of transported cargo and in worst cases also to traffic safety.

The tests also showed that if the short ratchets are used, the elongation of the complete lashing straps under load is higher in comparison with cases when long ratchets are used. We also must say that two out of the eight tested ratchets had severe quality problems, where the split pin of the ratchet AFL3

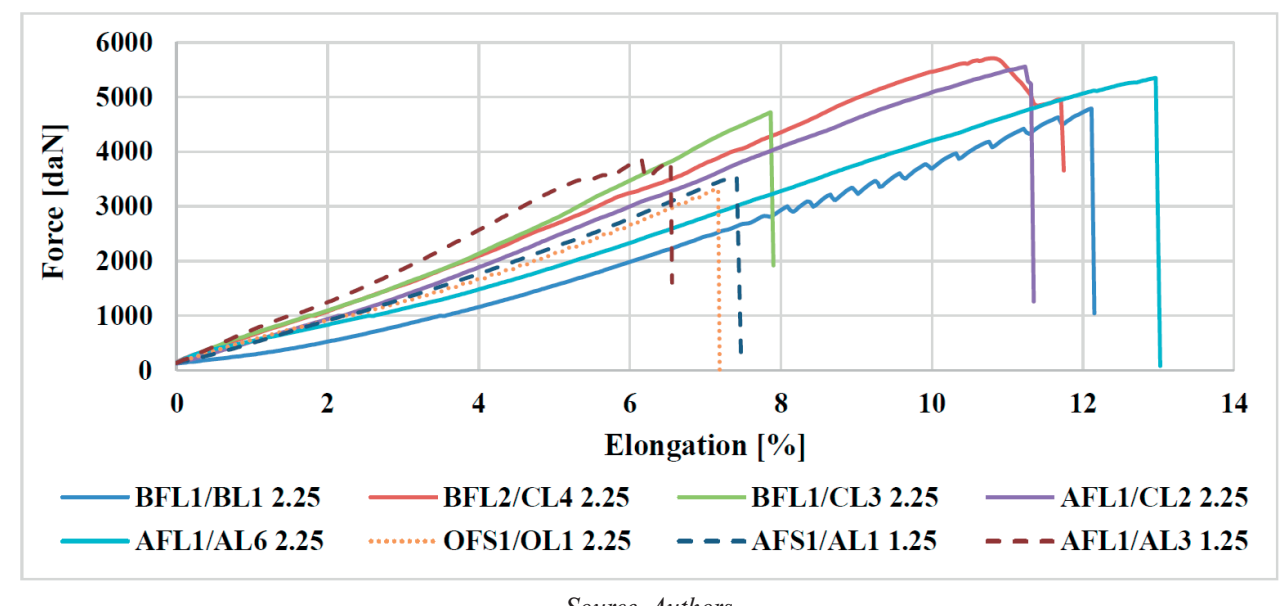

Source: Authors

Fig. 6 Run of the force and elongation of selected straps during the strength tests (samples with "1.25" in legend were tested with 11/4 turns of winding in a ratchet and those with "2.25" were tested with 21/4 turns of winding in a ratchet) 
broke already during the first cycle of cyclic loading tests at force $1473 \mathrm{daN}$ (significanlty below the lashing capacity) and the end hook of the ratchet BFL1 was broken into 4 parts at force $4724 \mathrm{daN}$. Next ratchet BFL2 was also the weakest part of tested combination, although it met the test requirements, because the partial break occured upon the level of 2 LC. However, the usual type of break of the complete lashing strap is a break of webbing loose end, near the ratchets rotating axis, where a winding ends. Results of the tests point at the fact that for good securing of cargo in practice it is needed to pay attention to a quality of used tensioning devices and end fittings, as well as to correct quantity of winding of a strap in tensioning ratchets, because these factors significantly affect the characteristics of lashing straps.

\section{Acknowledgement}

This publication is the result of the project implementation: Centre of excellence for systems and services of intelligent transport, ITMS 26220120028 supported by the Research \& Development Operational Programme funded by the ERDF.
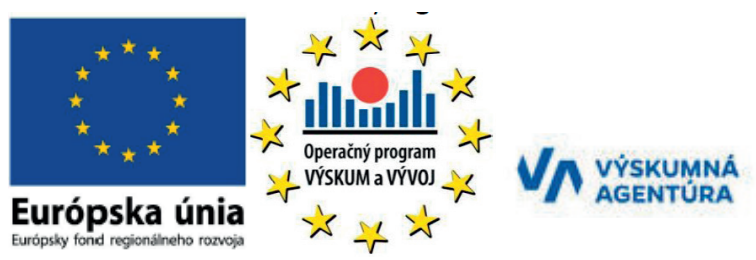

"We support research activities in Slovakia / This project is co-financed by the European Union"

\section{References}

[1] JAGELCAK, J.: Reduction of Lashing Strap Strength (in Slovak). Truck \& Business: Magazine for Road Transport Enterprise Strategy, vol. 8, No. 2, 2015, 58-59, ISSN 1337-897X.

[2] ZAMECNIK, J., JAGELCAK, J., SOKJER-PETERSSEN, S.: Comparison of Acceleration Acting on Cargo in Front and in Rear Part of Semi-Trailer during Braking with and without using the Systems ABS/EBS, Communications - Scientific Letters of the University of Zilina, vol. 18, No. 2, 2016, 76-82, ISSN 1335-4205.

[3] ZAMECNIK, J., JAGELCAK, J.: The Stress of Lashing Points in Full-Loaded 3.5-Tonne Van During Emergency Braking. Logi: Scientific J. on Transport and Logistics, vol. 6, No. 1 2015, 136-152, ISSN 1804-3216.

[4] POLIAK, M., KOMACKOVA, L., SEMANOVA, S., HERNANDEZ, S., JASKIEWICZ, M.: Defining the Influence of the Support of Bus Service on Road Safety, Communications - Scientific Letters of the University of Zilina, vol. 18, No. 2, 2016, 83-87, ISSN 1335-4205.

[5] JAGELCAK, J., ZAMECNIK, J.: Quality and Testing of Lashing Straps (in Slovak). Truck \& Business: Magazine for Road Transport Enterprise Strategy, vol. 8, No. 4, 2015, 72-75, ISSN 1337-897X.

[6] EN 12 195-2:2000. Load Restraint Assemblies on Road Vehicles. Safety, Part 2: Web lashing made from man-made fibres, 2000

[7] KUBANOVA, J., SCHMIDT, C.: Multimodal and Intermodal Transportation Systems, Communications - Scientific Letters of the University of Zilina, vol. 18, No. 2, 2016, 104-109, ISSN 1335-4205.

[8] IMO/ILO/UNECE Code of Practice for Packing of Cargo Transport Units (CTU Code), 2014

[9] JAGELCAK, J.: Loading and Securing of Cargo in Road Transport (in Slovak), EDIS : University of Zilina, 2015, ISBN 97880-554-1083-8

[10] HVOJNIK, T.: Cyclic Loading Tests of Selected Lashing Straps According to the Standard EN 12 195-2 (in Slovak), Bachelor thesis (supervisor J. Jagelcak, reviewer J. Zamecnik), Zilina, 2016

[11] LIPKA, M.: Strength Tests of Selected Lashing Straps According to the Standard EN 12 195-2 (in Slovak), Bachelor thesis (supervisor J. Jagelcak, reviewer J. Zamecnik), Zilina, 2016. 